\title{
DIGNIDAD DEL HOMBRE EN LA GAUDIUM ET SPES
}

\section{César Buendía* \\ Universidad Católica Sedes Sapientiae}

Resumen: En el presente ensayo se pondrá de manifiesto cómo el Concilio Vaticano II, a través de su Constitución Pastoral Gaudium et Spes, declara su antropología, por mejor decir, la de la Iglesia, la bíblica, la revelada. Por medio de un análisis detenido de los puntos fundamentales de este documento se pretende rescatar, como primordial y relevante para la humanidad, el hecho de reconocer que el hombre necesita de Cristo para que ilumine su existencia, sacudida por cambios incomprensibles y exigentes, y por la misma historia, que es lugar de revelación de Dios y de respuesta humana. Comprender la Providencia y dejar claro que el hombre es amado, imagen e hijo de Dios, no solo da una unidad y un equilibrio al ser humano, sino que se convierte en punto de apoyo para interpretar todos los problemas que constantemente desafían a los hombres, y que desde el ateísmo — teórico o práctico- no tienen solución.

* César Antonio Buendía Romero es sacerdote y doctor en Teología por la Facultad de Teología de Valencia. Es licenciado en Pedagogía por la Universidad de Valencia. Sus principales temas de estudio han sido la Teología de la Liberación Latinoamericana y la Teología de los sacramentos en santo Tomás de Aquino. Durante varios años fue secretario de la Comisión del Clero de la Conferencia Episcopal Peruana. Ha ejercido la docencia en la Facultad de Teología Pontificia y Civil de Lima, en el ISET Juan XXIII y en la Facultad de Teología Redemptoris Mater. Actualmente, dicta las cátedras en temas teológicos y lenguas bíblicas en la Universidad Católica Sedes Sapientiae. Además, forma parte del Gabinete Pedagógico de la Facultad de Ciencias de la Educación y Humanidades de la misma casa de estudios, donde lleva a cabo la coordinación de la carrera de Educación Secundaria, Filosofía y Religión. 
Palabras Clave: vocación, misión, cambios, ideologías, ciencia, desequilibrio, Providencia, antropología, hombre, Cristo.

\section{MAN'S DIGNITY IN THE GAUDIUM ET SPES}

AвSTRaCt: In this essay we will show how the Second Vatican Council states its anthropology through its Pastoral Constitution Gaudium et Spes, that is to say, that of the Church, the Bible, the revealed. Through careful analysis of the key points in this paper we will rescue as primary and relevant to humanity acknowledgement the fact that the man needs Christ to enlighten his existence, affected by incomprehensible and demanding changes, and for the sake of history, the place for God's revelation and human response. Understanding of the Providence and making clear that man is loved as image and God's child, not only gives unity and balance to the human being, but becomes a fulcrum to interpret all the problems that constantly challenge men, those which through atheism -theoretical or practical- have no solution.

KeYwords: vocation, mission, change, ideologies, science, imbalance, Providence, anthropology, man, Christ. 
Hace tiempo comparé la misión de la Iglesia con la imagen de las dos manos (de Dios y de Adán) tomada del célebre fresco de Miguel Ángel sobre la creación del hombre. La Iglesia está llamada a ser esa mano que se acerca al hombre y le hace ser hombre [...] el encuentro de la mano de Dios (el Espiritu de Dios, como sugería Jesús) con esa otra mano que demanda crecer y que al crecer se cristifica. Incluso esa otra mano que recibe resulta ser también mano anónima de Cristo, el Don exterior de Dios, a quien se hace todo cuanto de bien hacemos al ser humano [...]. El encuentro de las dos manos es siempre una realidad sacramental y la Iglesia es esa porción del mundo en que se actúa esa sacramentalidad anónima de lo real, se actúa porque...se convierte en norma de conducta.

González Faus

\section{1. «LOS GOZOS Y LAS ESPERANZAS, LAS TRISTEZAS Y LAS ANGUSTIAS DE LOS HOMBRES SON LOS DE LOS DISCÍPULOS DE LA IGLESIA. NADA HAY VERDADERAMENTE HUMANO QUE NO ENCUENTRE ECO EN SU CORAZÓN» (GS 1)}

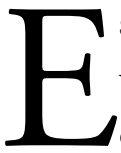

sta oración inicial de la Constitución nos pone ante los ojos la vocación de servicio y amor de la Iglesia. Tal solicitud, que se deriva de la misión de la Iglesia y de su pasión por el hombre, no indica, por necesidad, la solidaridad de la Iglesia con el hombre en su pecado. Tampoco la justificación de las angustias derivadas del mismo, sino que indica el amor de Cristo del que la Iglesia es sacramento.

La solidaridad es cargar con el pecado del mundo, pero no para que continúe en él. El Cordero de Dios quita el pecado del mundo cargando con él, es decir, haciéndose responsable de él. Como si Él mismo lo hubiera hecho. Como el buen samaritano. Eso es lo que el Concilio quiere que 
haga la Iglesia. Quiere salvar al hombre y llevarlo al reino de Dios. Y sabe que posee la Buena Nueva, que es el amor de Dios, y la gracia, que es su presencia. ${ }^{1}$

\section{2. «ESTE CONCILIO SE DIRIGE A TODOS LOS HOMBRES»(GS 2)}

En este sentido, el destinatario es la humanidad. No porque todos van a entender la palabra de la Iglesia, sino porque la Iglesia los entiende a ellos, y porque tiene para ellos la Noticia que, una vez aceptada, les salva. Por tanto, el anuncio universal de la salvación significa el destino universal de la salvación. No se trata en principio de los destinatarios de la palabra conciliar, aunque posteriormente la Gaudium et Spes sí lo intentará. ${ }^{2}$ Se trata de la intención universal de la Palabra de Cristo, y por ello de la palabra del Concilio.

1 «Los gozos y las esperanzas, las tristezas y las angustias de los hombres de nuestro tiempo, sobre todo de los pobres y de cuantos sufren, son a la vez gozos y esperanzas, tristezas y angustias de los discípulos de Cristo. Nada hay verdaderamente humano que no encuentre eco en su corazón. La comunidad cristiana está integrada por hombres que, reunidos en Cristo, son guiados por el Espíritu Santo en su peregrinar hacia el reino del Padre y han recibido la buena nueva de la salvación para comunicarla a todos. La Iglesia por ello se siente íntima y realmente solidaria del género humano y de su historia» (GS 1).

2 GS 2: Por ello, el Concilio Vaticano II, tras haber profundizado en el misterio de la Iglesia, se dirige ahora no solo a los hijos de la Iglesia católica y a cuantos invocan a Cristo, sino a todos los hombres, con el deseo de anunciar a todos cómo entiende la presencia y la acción de la Iglesia en el mundo actual.

Tiene pues, ante sí la Iglesia al mundo, esto es, la entera familia humana con el conjunto universal de las realidades entre las que esta vive; el mundo, teatro de la historia humana, con sus afanes, fracasos y victorias; el mundo, que los cristianos creen fundado y conservado por el amor del Creador, esclavizado bajo la servidumbre del pecado, pero liberado por Cristo, crucificado y resucitado, roto el poder del demonio, para que el mundo se transforme según el propósito divino y llegue a su consumación. 


\section{3. «EL GÉNERO HUMANO, ADMIRADO DE SUS PROPIOS DESCUBRIMIENTOS Y DE SU PROPIO PODER» (GS 3)}

Resalta el Concilio la admiración que provoca en todos los hombres el poder, sobre todo, en relación a los descubrimientos técnicos del género humano. A la vez, después de las guerras mundiales, resalta la posibilidad del uso perverso de ese poder.

Se pregunta, así, el mundo, por el futuro («la evolución del mundo presente»), por la Providencia, por la misión del hombre, el sentido de sus esfuerzos. Asimismo, se interroga acerca del modo de poder usar positivamente ese poder que es la libertad.

Es en este punto, donde el Concilio quiere ayudar y puede hacerlo: la buena noticia es el amor de Dios, y este mundo la necesita escuchar; hace falta escuchar al Espíritu. Es necesaria la renovación del hombre para que el mundo cambie. ${ }^{3}$ Pero el clima es el diálogo: «No puede dar mayor prueba

3 En nuestros días, el género humano, admirado de sus propios descubrimientos y de su propio poder, se formula con frecuencia preguntas angustiosas sobre la evolución presente del mundo, sobre el puesto y la misión del hombre en el universo, sobre el sentido de sus esfuerzos individuales y colectivos, sobre el destino último de las cosas y de la humanidad. El Concilio, testigo y expositor de la fe de todo el Pueblo de Dios congregado por Cristo, no puede dar prueba mayor de solidaridad, respeto y amor a toda la familia humana que la de dialogar con ella acerca de todos estos problemas, aclarárselos a la luz del Evangelio y poner a disposición del género humano el poder salvador que la Iglesia, conducida por el Espíritu Santo, ha recibido de su Fundador. Es la persona del hombre la que hay que salvar. Es la sociedad humana la que hay que renovar. Es, por consiguiente, el hombre; pero el hombre todo entero, cuerpo y alma, corazón y conciencia, inteligencia y voluntad, quien será el objeto central de las explicaciones que van a seguir.

Al proclamar el Concilio la altísima vocación del hombre y la divina semilla que en este se oculta, ofrece al género humano la sincera colaboración de la Iglesia para lograr la fraternidad universal que responda a esa vocación. No impulsa a la Iglesia ambición terrena alguna. Solo desea una cosa: continuar, bajo la guía del Espíritu, la obra misma de Cristo, quien vino al mundo para dar testimonio de la verdad, para salvar y no para juzgar, para servir y no para ser servido (GS 3). 
de solidaridad, respeto y amor por toda la familia humana que la de dialogar con ella acerca de todos estos problemas».

Señala, a su vez, el Concilio que pone la esperanza en la semilla de eternidad que Dios ha puesto en el corazón humano. Es decir, esa vocación a Cristo que es el primogénito de entre los mortales.

\section{4. «SITUACIÓN DEL HOMBRE EN EL MUNDO DE HOY» (GS 4-8)}

Aquí es donde se habla de «escrutar los signos de los tiempos e interpretarlos a la luz del evangelio». ${ }^{4}$ Es una frase casi simbólica de todo lo que pasó después. ¿Qué significaba en ese momento esta frase?

Realmente los signos de los tiempos son los elementos significativos del mundo contemporáneo que se convierten en desafíos para la evangelización. Estos signos son como palabras de la Providencia que habla en la historia. La historia no es algo incomprensible, sino que, a la luz del Evangelio, se ve como el escenario de la acción, de la gracia y de la libertad; así como de la acción de Dios.

El optimismo del Concilio parte de esa convicción fundamental que afirma que «Dios es bueno» y dirige la historia. No obstante, también hay otra convicción: Cristo es el centro de la historia, es decir, desde la Encarnación todo ha cambiado de signo. Ella, la historia, plantea en cada generación algo nuevo, porque surgen nuevas realidades, a veces dramáticas —dice el Concilio (este tema vuelve a aparecer en el número 11, cuando se hable de la vocación del hombre)—. Sin embargo, nosotros poseemos lo

4 Para cumplir esta misión es deber permanente de la Iglesia escrutar a fondo los signos de la época e interpretarlos a la luz del Evangelio. De esta forma, acomodándose a cada generación, la Iglesia pueda responder a los perennes interrogantes de la humanidad sobre el sentido de la vida presente y de la vida futura y sobre la mutua relación de ambas. Es necesario por ello conocer y comprender el mundo en que vivimos, sus esperanzas, sus aspiraciones y el sesgo dramático que con frecuencia le caracteriza (GS 4). 
perenne. El Evangelio es para siempre, porque Cristo es para ayer, para hoy y para siempre, porque vive siempre (Heb 7,25), ${ }^{5}$ y responde a esas realidades. Aquellas que provienen de los signos de los tiempos, porque responde a los interrogantes profundos, que son perennes, y que están, de algún modo, profetizados en el mismo Evangelio (GS 4).

¿Cuáles son esos signos? El Concilio los tendrá en cuenta siempre, y ahora los va a resumir en una serie de cambios que se observan en el mundo contemporáneo.

\section{CAMBIOS}

El Concilio describe algunos de esos cambios a los que va a responder, y a los que caracteriza como rápidos y profundos, particularmente. Esos cambios amenazan o son oportunidad de mejora. Así pues, no solo condicionan al hombre con su fuerza, sino que en cierto sentido le enfrentan con decisiones inaplazables. Hay un efecto retroactivo en esos cambios, provocados por el mismo hombre, sobre el mismo hombre (cf. La revolución de la ciencia, N. $5) .^{6}$

Por ello, dice el Concilio, que "el hombre, deseando" conocer su intimidad espiritual y, cada vez, estando más desconcertado, y descubriendo las leyes de la vida social, pero no sabiendo cómo orientarla, vive la falta de unidad y solidaridad entre los hombres. Estos se encuentran divididos por

5 Me gusta introducir aquí lo que explica a este respecto San Fulgencio de Ruspe: «Fijaos en lo que decimos: por nuestro señor Jesucristo [...]. Por su medio ofrecemos continuamente a Dios un sacrificio de alabanza [...]» (cf. Carta 14, 36-37: CCL 91, 429-431).

6 Seguramente está pensando en los efectos de las nuevas máquinas sobre los hombres en la Segunda Guerra Mundial; pero, en el fondo, se trata de la soberbia por la que el hombre se cree Dios y todo lo destruye. 
ideologías y confundidos por graves errores y profundas simas de avaricia. Aumentando así, las diferencias abismales entre sociedades adelantadas y atrasadas (ver también los cambios en el orden social del N. 6), como también las nuevas esclavitudes sociales y psicológicas. Además, los hombres aparecen «divididos» en sus pensamientos e «ideologías, que intentan explicar» el sentido del hombre sobre la tierra. Muchas veces se pretende encontrar el significado de la existencia sin tener en cuenta a Dios, como si fuéramos nuestros propios autores.

No hay verdadera comunicación porque no hay amor. Y esa falta de amor hace que se quiera el orden social más perfecto, sin que «avance paralelamente el mejoramiento de los espíritus». Dicha situación es imposible. Siempre, si el espíritu no mejora, crecerán las diferencias y las injusticias.

Reseñemos algunos otros cambios profundos (GS 5). Estos son los que siguen: (a) en el mundo de la técnica, conquista de los espacios interplanetarios; (b) conocimiento de la historia; (c) planificación del futuro; (d) progresos biológicos, psicológicos, sociales; (e) medios de comunicación y (f) ordenación demográfica.

Todos estos cambios el hombre lo experimenta a gran velocidad. Se propician nuevos problemas, nuevos análisis y nuevas síntesis que generan una concepción muy dinámica de la misma historia.

\subsection{Cambios EN EL ORden SOCIAL (GS 6)}

Dentro de la vida social, el hombre percibe fuertes cambios que repercuten en los aspectos esenciales de su humanidad. A continuación los detallamos: 
- La desarticulación de las antiguas sociedades, como la aldea o la familia, que son absorbidas por la vorágine de las comunicaciones, las migraciones o la globalización, y por el desarraigo de las nuevas generaciones.

- La confusión de valores y la globalización de las ideas que - incluso en los lugares más ocultos y en los pueblos más alejados - proviene de la participación mal asimilada en la comunidad internacional. Esta situación desvincula a la gente de su realidad y de sus parientes, con lo cual la gente se despersonaliza.

- Como signo positivo el Concilio reseña el hambre de libertad que se da en todos.

\subsection{CAMbios PSICOLÓgicos, MORALES Y RELIGIOSOS (GS 7)}

Este mundo es contradictorio. Sabe estimar lo que vale, y sabe que son necesarios los valores; es decir, la sujeción a valores universales y objetivos, entre otras cosas, porque es la única manera de entenderse. Esto es porque no se va a negar que el valor de la persona humana supera a todo lo que puede haber, especialmente lo material. Pero, por otro lado, en muchas ocasiones, se cae en el escepticismo. Ciertamente, los valores tienen como sustento el valor sin comparación, que es Dios. No se puede hablar de objetividad cuando se vive sin Dios.

La misma persona humana tiene un valor superior a sus obras, y es el amor que Dios le tiene, y su destino eterno. Pues bien, «Muchedumbres se alejan de la religión» (GS 7). La negación de Dios no constituye un hecho insólito, como ocurría en el pasado. 
- La causa es una idea equivocada de Dios, como aquel que no interviene en el devenir de las cosas (el Dios dormido de los deístas, el Dios cruel o el Dios impotente). Es evidente que los que piensan así de Dios no van a confiar en la Providencia divina para arriesgarse a seguir ese camino de sacrificio que Dios le señala, camino en el que Dios aparece.

- Las consecuencias de esa confusión son el hedonismo (carpe diem), el materialismo, el inmanentismo y el miedo al futuro. En ese sentido es evidente que la demografía parece un peligro, porque los niños son el futuro. El efecto es la tentación del aborto y la eutanasia. $^{7}$

-En cuanto a los jóvenes, la diversidad, en sí buena, se convierte a veces en un caos. Los jóvenes, los más amados, son también aquellos que se dejan tentar más fácilmente por ideas o por errores que se extienden entre ellos rápidamente. Entran fácilmente en la sociedad y en ocasiones no se dejan educar, como si ellos fueran los poseedores de la verdad, o, por mejor decir, se dejan educar por cualquiera. Intentar controlar eso es como intentar poner puertas al campo. El desaliento cunde en la Iglesia que es vista muchas veces

7 En el fondo es determinante la expansión, muchas veces inusitada, de las ideologías ateas o del ateísmo práctico, tan lleno de hedonismo.

El ateísmo deja al ser humano solo, sin Dios, no solo con la conciencia de que debe planificar el futuro, cuando lo cierto es que apenas puede el ser humano seguir el curso de la misma historia. La hostilidad, la competencia salvaje, la marginación creciente y los desequilibrios resultantes del escepticismo y del egoísmo, no deberían extrañar a nadie. Porque los medios masivos de comunicación, que el Concilio apenas preveía, y que ahora se han convertido en algo que asusta, comunican las ideas a velocidades vertiginosas (6). El mundo se ha vuelto así urbano, pero no por ello inclusivo, no por ello comprensible, sino más bien una gran Babel. Es difícil ver a Dios en ello, pero está. 
como algo no adaptado a las condiciones del mundo moderno y que ve cómo muchedumbres inmensas viven lejos de ella (GS 7).

- La familia se desune (GS 8), primero por la crisis generacional, y luego por ese hedonismo y esa desconfianza de las verdades que la Iglesia transmite, y que han regido a las generaciones mayores (la prioridad del amor conyugal, la perennidad del vínculo, la necesidad del control de las pasiones y el sentido de todo ello: el amor a Dios y a su voluntad, con la esperanza en la vida eterna). Es por eso, que aparece un sentido equívoco de la misma libertad humana. ${ }^{8}$

\section{INTENCIÓN DEL CONCILIO}

El Concilio va a intentar «responder» a esos desequilibrios profundos con varias ideas (GS 9). La primera es la confianza en la Providencia, como he señalado ya. Esa confianza hace ver con alegría que las excelentes aspiraciones de la humanidad, puestas por la mano del Creador en el corazón del hombre, están vivas. El Concilio señala, entre otras ideas, las que siguen:

- la necesidad de un orden justo (político, económico y social) al servicio del hombre y su dignidad,

- la necesidad de una unidad universal,

- la valoración de todo ser humano, por encima del sexo o de la condición social, y por tanto, la igualdad de oportunidades en educación y cultura,

-el hambre y la sed de libertad.

8 Las ideas que en ese momento influían en la sociedad eran sobre todo las ideas marxistas o existencialistas. Tomadas como respuestas verdaderas a los profundos interrogantes del hombre, y que intentaban penetrar en la cultura, el arte y la legislación. 
- La necesidad de una cultura de comprensión universal para dirigir esas fuerzas enormes que ha desencadenado y que también pueden aplastar al hombre (la fuerza de la técnica y la ciencia y las comunicaciones globales, la fuerza de las ideas, etc.)

- Valoración de lo que hay de irredento en las aspiraciones humanas: «Pero bajo todas esas reivindicaciones se oculta una aspiración más profunda y universal [...] una vida plena y libre, digna del hombre» (GS 9), es decir, lo que solo de Dios procede. El Concilio aquí indica la vocación humana al Infinito.

\section{MYSTERIUM PECCATI ${ }^{9}$}

«En realidad de verdad, los desequilibrios que fatigan al mundo moderno están conectados con ese otro desequilibrio fundamental que hunde sus raíces en el corazón humano» (GS 10). Al respecto, el Concilio se referirá a tres desequilibrios por los que padece la humanidad, los cuales señalamos a continuación:

- La limitación humana y la vocación ilimitada. Es en realidad algo positivo, porque es la vocación de eternidad. ${ }^{10}$ Se encuentra inscrita en el corazón humano, y se podría identificar con el deseo de Dios, que no tolera el límite. La limitación no es negativa, porque nos invita a buscar al que la puede superar, a Dios.

9 GS 10. Ver también el N. 13: «Creado por Dios en la justicia, el hombre, sin embargo, por instigación del demonio, en el propio exordio de la historia, abusó de su libertad, levantándose contra Dios y pretendiendo alcanzar su propio fin al margen de Dios».

10 «A fuer de criatura, el hombre experimenta múltiples limitaciones; se siente, sin embargo, ilimitado en sus deseos y llamado a una vida superior» (GS 10). 
- La dificultad de sabiduría en el juicio moral. Por la libertad, que le obliga a realizar el juicio moral, el ser humano tiene la posibilidad de elegir lo mejor. Sin embargo, no siempre es fácil ese juicio, porque en ocasiones se le presentan los bienes inferiores como más atractivos y las propias fuerzas como incapaces de resistirse. ${ }^{11}$ - La herencia del pecado, el original, el ajeno y el propio. Esto es negativo; se trata del desequilibrio causado por el pecado del hombre que ha provocado en él la división profunda entre lo que hace y lo que está llamado por Dios a hacer y vivir. Esto en realidad esclaviza al hombre, porque hace lo que no quiere. ${ }^{12}$

Inmediatamente el Concilio indica que ese tercer desequilibrio es la fuente del mal que experimenta la sociedad. El Concilio está diciendo que la solución también está en el mismo sentido; en curar al hombre mismo, profundamente herido, profundamente necesitado de Dios. Así el Concilio indica desde aquí que solo Dios, en Cristo, es la clave de la solución de los problemas humanos, aunque lo señalará explícitamente más tarde en la profesión de fe del número $10 .{ }^{13}$

11 «Atraído por muchas solicitaciones, tiene que elegir y que renunciar» (GS 10).

12 «Más aún, como enfermo y pecador, no raramente hace lo que no quiere y deja de hacer lo que querría llevar a cabo» (GS 10).

13 "Cree la Iglesia que Cristo, muerto y resucitado por todos, da al hombre su luz y su fuerza por el Espíritu Santo a fin de que pueda responder a su máxima vocación y que no ha sido dado bajo el cielo a la humanidad otro nombre en el que sea necesario salvarse. Igualmente cree que la clave, el centro y el fin de toda la historia humana se halla en su Señor y Maestro. Afirma además la Iglesia que bajo la superficie de lo cambiante hay muchas cosas permanentes, que tienen su último fundamento en Cristo, quien existe ayer, hoy y para siempre. Bajo la luz de Cristo, imagen de Dios invisible, primogénito de toda la creación, el Concilio habla a todos para esclarecer el misterio del hombre y para cooperar en el hallazgo de soluciones que respondan a los principales problemas de nuestra época» (GS 10). 
Sigue el Concilio haciendo un análisis de las consecuencias de ese estado y de las soluciones que el hombre busca al margen de Dios. Estas son las que siguen:

-El materialismo práctico. ${ }^{14}$

- La inconsciencia motivada por la urgencia de los problemas. ${ }^{15}$

-El pelagianismo del progreso científico o el materialismo dialéctico (materialismo teórico). ${ }^{16}$

-El existencialismo pesimista, el escepticismo o el subjetivismo. ${ }^{17}$

Pero, como esas soluciones son falsas porque fallan por la base, es decir, porque en vez de cambiar la relación del hombre con Dios, solo cambian las circunstancias materiales que rodean al ser humano, las cosas quedan igual. Y ni siquiera eso se consigue. Porque la injusticia, la corrupción, la mentira y la infidelidad hacen imposible la confianza y la justicia, que son las bases del crecimiento económico de la misma sociedad. La muerte y la injusticia no han sido vencidas, porque no dependen únicamente del esfuerzo humano. En el corazón humano se ha implantado un egoísmo ciego que impide ver a Dios y al prójimo. Por eso, Dios es el

14 «Muchísimos son los que, tarados en su vida por el materialismo práctico, no quieren saber nada de la clara percepción de este dramático estado» (GS 10).

15 «O bien, oprimidos por la miseria, no tienen tiempo para ponerse a considerarlo» (GS 10).

16 «Otros esperan del solo esfuerzo humano la verdadera y plena liberación de la humanidad y abrigan el convencimiento de que el futuro del hombre sobre la tierra saciará plenamente todos sus deseos» (GS 10).

17 «Y no faltan, por otra parte, quienes, desesperando de poder dar a la vida un sentido exacto, alaban la insolencia de quienes piensan que la existencia carece de toda significación propia y se esfuerzan por darle un sentido puramente subjetivo» (GS 10). 
único que puede cambiar el ser del hombre, tanto con su Palabra, que es Cristo, como con su gracia.

Pero no todo está perdido. Dios hizo bueno al hombre. El pecado es una enfermedad. Y eso se cura. Por eso, el ser humano no deja de hacerse las preguntas que precisamente le hacen humano, porque son preguntas inteligentes.

El Concilio defiende que detrás de todas las preocupaciones y deseos del hombre contemporáneo están «los interrogantes profundos del hombre». Estos son los siguientes:

- ¿Qué es el hombre? (GS 10).

- ¿Cuál es el sentido del dolor, del mal, de la muerte, que, a pesar de tantos progresos hechos, subsisten todavía? (GS 10).

- ¿Qué valor tienen las victorias logradas a tan caro precio? (GS 10).

- ¿Qué puede dar el hombre a la sociedad? (GS 10).

- ¿Qué puede esperar de ella? (GS 10).

- ¿Qué hay después de esta vida temporal? (GS 10).

A todo ello responde el Concilio con la "profesión de fe», que ya hemos reseñado y que constituye el texto más importante de la Gaudium et Spes, aunque es incomprensible sin lo demás.

\section{CREE LA IGLESIA}

La Iglesia cree que «Cristo, muerto y resucitado por todos, da al hombre su luz y su fuerza por el Espíritu Santo a fin de que pueda responder a su máxima vocación y que no ha sido dado bajo el cielo a la humanidad otro nombre en el que sea necesario salvarse» (GS 10). 
Es necesario señalar aquí que hay una vocación al encuentro, que se percibe ya en el encuentro con el otro ser humano, imagen de Dios. Pero solo Dios puede saciar el corazón humano. Ese encuentro no es abstracto simplemente. Es el encuentro con el amor del que fue muerto por los hombres y vino perdonando. Es decir, es histórico. Y da fuerzas, es la gracia $^{18}$ que acontece en el hombre, de manera que la Iglesia permanece fortalecida. Así «Igualmente cree que la clave, el centro y el fin de toda la historia humana se halla en su Señor y Maestro. Afirma además la Iglesia que bajo la superficie de lo cambiante hay muchas cosas permanentes, que tienen su último fundamento en Cristo, quien existe ayer, hoy y siempre» (GS 10).

Después nos dirá la GS 39 que quedará la caridad y sus obras. ${ }^{19}$ Eso es lo permanente que quedará sin lo transitorio, que pasará. Así, «Bajo la luz de Cristo, imagen de Dios invisible, primogénito de toda la creación, el Concilio habla a todos para esclarecer el misterio del hombre y para cooperar en el hallazgo de soluciones que respondan a los principales problemas de nuestra época».

18 Se trata del Espíritu Santo, que es Dios y que el hombre no puede darse a sí mismo. Su mensaje es el amor que quiere contagiarse. Su mensaje es la esperanza incluso en medio del dolor y la muerte. Si se nos contagia su amor vivimos el mismo Espíritu de Cristo en la cruz.

19 Por ello, aunque hay que distinguir cuidadosamente progreso temporal y crecimiento del reino de Cristo, sin embargo, el primero, en cuanto puede contribuir a ordenar mejor la sociedad humana, interesa en gran medida al reino de Dios.

Pues los bienes de la dignidad humana, la unión fraterna y la libertad, en una palabra, todos los frutos excelentes de la naturaleza y de nuestro esfuerzo, después de haberlos propagado por la tierra en el Espíritu del Señor y de acuerdo con su mandato, volveremos a encontrarlos limpios de toda mancha, iluminados y trasfigurados, cuando Cristo entregue al Padre el reino eterno y universal: «Reino de verdad y de vida; reino de santidad y gracia; reino de justicia, de amor y de paz». El reino está ya misteriosamente presente en nuestra tierra; cuando venga el Señor, se consumará su perfección. 


\section{UN PEQUEÑO PARÉNTESIS. DECLARACIÓN DE INTENCIONES Y PROCEDIMIENTOS}

Ahora, creo yo, cambia la música. Los interrogantes anteriores eran universales y por eso estaban por encima del tiempo, aunque los provocaban los cambios evidentes en la sociedad.

Vuelve el Concilio a proponer hablar de cosas más históricas (GS 10). Vuelve a hablar de los signos de los tiempos, que aparecen ahora a una nueva luz. Si en el número 4 eran acontecimientos históricos que debían ser discernidos a la luz del Evangelio, ahora son palabras providenciales de Dios en la historia, signos de su presencia. ${ }^{20}$

La fe aparece como una luz que hace discernir la voluntad de Dios en la historia. Es decir, ilumina esos signos que son los acontecimientos históricos y que están misteriosamente conducidos por la Providencia divina.

Está claro que no quiere el Concilio ver la historia como fruto del azar o de la necesidad. Lo quiere ver como una Palabra que viene de Dios.

No se trata, evidentemente, de nuevas palabras o revelaciones. Se trata más bien de ver la bondad de Dios, tantas veces manifestada, y conocida plenamente en el don que Cristo hizo de sí mismo, en los acontecimientos de la historia.

Los signos de los tiempos van a ser los motivos de la palabra de la Iglesia a partir de este momento de la Gaudium et Spes. Sin embargo, el Concilio habla también de "proponer soluciones» a los problemas del hombre contemporáneo. Esas soluciones son «plenamente humanas». Es

20 «El Pueblo de Dios, movido por la fe, que le impulsa a creer que quien lo conduce es el Espíritu del Señor, que llena el universo, procura discernir en los acontecimientos, exigencias y deseos, de los cuales participa juntamente con sus contemporáneos, los signos verdaderos de la presencia o de los planes de Dios». 
decir, se trata de reconocer lo bueno, porque lo bueno es universal, y relacionarlo con Dios, con su «fuente divina». Dios es el autor de la razón, y las verdades y verdaderos valores, que esta descubre rectamente, no se pueden oponer a la fe, y entonces se vuelve más humano, más cercano, más factible, más racional.

Lo que Dios propone como bueno es realmente bueno, y corresponde a la racionalidad y a la ley natural humana. Pero las limitaciones, tanto estructurales como históricas del ser humano, impiden conseguir aquello que Dios quiso para el hombre. Por eso, Dios no está lejos del ser humano, sino muy cerca. Y la fe aportará, por su parte, algo que sin ella no uno conseguiría conocer a Cristo y su gracia, y con ellos, un motivo superior para seguir viviendo.

La fe, de esa forma, señala el futuro, nos dice adónde vamos, y sin ese futuro no hay dirección, y donde no hay dirección no hay criterio. Por otro lado, sin Cristo no conocemos verdaderamente al hombre. Por eso, es necesario escuchar a Cristo, el hombre tal como Dios lo quiso. 7 Jesús revela al hombre qué es el hombre. La fe ilumina la oscuridad de la historia, desvela su fin, y, habida cuenta del pecado original, purifica y arroja luz sobre la conducta del hombre, frecuentemente injusta y perversa (cf. GS 22). ${ }^{21}$

21 El Concilio desarrolla desde aquí su interrogante principal. Recordemos que era sobre el futuro. El futuro nos pone en crisis respecto de los ídolos del presente. Poniéndose bajo la acción del Espíritu y renovando su fe en la Iglesia conducida por Él, se va a disponer a discernir los acontecimientos a la luz del futuro manifestado en la resurrección de Cristo. Valorará también las exigencias y deseos de los hombres para responder concretamente a ellos, reconociendo lo positivo señalando su relación con Dios y purificándolo de toda desviación que nace del Pecado. Después va a afirmar el mutuo servicio que se hace la Iglesia y la humanidad y reafirmando que la misión de la Iglesia es religiosa, pero que por ello es plenamente humana. 
Por tanto, las cuestiones a tratar, a partir de la antropología que va a presentar la Gaudium et Spes, son tres. Estas son las siguientes:

- La tarea de la Iglesia en el mundo. Relaciones mutuas y servicio mutuo.

- Criterios rectos para actuar en la historia en favor del bien común.

- Sentido último de la acción humana.

\section{ANTROPOLOGÍA DE LA GAUDIUM ET SPES}

\subsection{El hombre, IMAGen de Dios}

Lo que había dicho hasta ahora es que a los interrogantes profundos del hombre responde Jesucristo. Por eso, el hombre solamente entiende su dignidad cuando ve en Cristo su origen y su destino (GS 12). Esa es la tesis fundamental que se repetirá en el número 22. Pero para explicar que corresponde a la experiencia universal, ahora va a partir de algo que presume universalmente admitido: «Creyentes y no creyentes están generalmente de acuerdo en este punto: todos los bienes de la tierra deben ordenarse en función del hombre, centro y cima de todos ellos» (GS 12).

Si esto es así, y nadie lo va a negar, el hombre, con razón, ve en sí mismo el misterio de su propia dignidad. Sabe que es la cima y el centro de la creación y que es el único bien en sí, en función del cual están todos los demás.

Pero el hombre reconoce que no se ha dado la vida a sí mismo, de modo que la pregunta sigue siendo la misma: «¿Qué es el hombre?». Y de la respuesta a esa pregunta dependerá su actuar y su felicidad misma. Porque 
si no responde se quedará vacío, sin sentido. Si responde sabrá hacia dónde caminar.

La Iglesia, con la Revelación, conoce la respuesta. El hombre es imagen de Dios. Es decir, es aquello que más revela a Dios en el mundo. Y lo revela cuando vive el amor, la entrega. Dirá más adelante que está llamado a ser hijo de Dios, es decir, es la única criatura a la que Dios ha amado por sí mismo (GS 24).22

Sin embargo, la experiencia nos dice que el desprecio del hombre ha causado muchos males. Pero la soberbia también. Cuando el hombre es medido por el dinero que gana, el pobre o el enfermo, el viejo o el niño, el loco o el perdedor son despreciados. Cuando el hombre se cree dios, se entrega a lo que no puede y después se deprime juzgándose por los resultados.

Pero si el hombre se define por su relación con Dios, es decir, con valores que le superan, trascienden y preceden, entonces su dignidad no consiste en oponerse a ellos, sino en vivirlos. E incluso el pecador se sabe amado. La Iglesia, pues, va a decirle al hombre contemporáneo que solo en Cristo sabe el hombre lo que es verdaderamente el hombre.

Todo hombre, pues, que no conoce a Cristo, está casi siempre equivocado sobre su vocación, sobre sus posibilidades, sobre el futuro, sobre los valores, sobre su valor propio y sobre todo. Esas equivocaciones son evidentes:

- Unos los exaltan como si el hombre fuera el dueño de la verdad y la fuente del bien (humanismos ateos).

22 GS 24: «Esta semejanza demuestra que el hombre, única criatura terrestre a la que Dios ha amado por sí mismo, no puede encontrar su propia plenitud si no es en la entrega sincera de sí mismo a los demás». 
- Otros se hunden en la desesperación, duda y ansiedad (existencialistas pesimistas).

Es inevitable para el Concilio la referencia implícita a las locuras cometidas en las últimas guerras, tanto por la rebeldía contra valores objetivos, superiores y absolutos, como por la exaltación egoísta. Sea del propio partido, pensamiento, raza o nación, que ha conducido también al desprecio de la vida humana y a la denigración del otro ser humano.

El hombre no es la fuente de la verdad, sino su siervo. Esta referencia a valores objetivos, anteriores al hombre y superiores a él (Dios), no degradan al hombre, sino que le hacen pisar tierra y encontrarse con la realidad. Dios es real. Por eso es real la esperanza.

Lo que viene posteriormente es una «declaración» de fe: El ser humano es lo siguiente:

- Imagen de Dios, con capacidad de relación con Dios, con libertad, con capacidad para el bien, fundamentalmente bueno, señor de la creación. ${ }^{23}$

- Ser social. Creado para amar a los demás, y sin ellos no puede realizarse a sí mismo. ${ }^{24}$

23 «La Biblia nos enseña que el hombre ha sido creado "a imagen de Dios", con capacidad para conocer y amar a su Creador, y que por Dios ha sido constituido señor de la entera creación visible para gobernarla y usarla glorificando a Dios [...] Dios, pues, nos dice también la Biblia, miró cuanto había hecho, y lo juzgó muy bueno» (Gen 1,31)» (GS 12).

24 «Pero Dios no creó al hombre en solitario. Desde el principio los hizo hombre y mujer (Gen 1,27). Esta sociedad de hombre y mujer es la expresión primera de la comunión de personas humanas. El hombre es, en efecto, por su íntima naturaleza, un ser social, y no puede vivir ni desplegar sus cualidades sin relacionarse con los demás» (GS 12). 
Estas dos dimensiones resultan sorprendentes por varios motivos. Nunca hasta ahora había definido ningún documento del magisterio, de esa importancia, de tal modo, la dimensión social del ser humano. Y menos la había puesto junto a la definición bíblica de «imagen de Dios» como si fuera evidente que esta es inseparable de aquella. Es por eso que podemos suponer que aquí hay una apuesta especial del Concilio.

El Concilio está definiendo la imagen de Dios con el amor al prójimo. Lo hemos visto antes en la referencia a GS 24 (cita 22). El hombre, creado libre, realiza la imagen de Dios en la historia amando a su prójimo. Ser imagen de Dios no es una esencia intemporal, sino un ser que da lugar a un cometido, a una misión del hombre. Dios es amor. Somos su imagen cuando vivimos en el amor. Recuerda mucho la primera carta de Juan $(4,7)$.

Creo que esto es una clave para comprender el resto del documento. Se ha dicho hasta la saciedad que el Concilio no es dogmático, oponiéndolo a ser pastoral. En realidad es que su dogma es este: lo pastoral es lo propio de la Iglesia, que se realiza en el tiempo, en la historia. Se ha superado así un pensamiento fixista, tanto de la Iglesia como del hombre.

Pero el Concilio, casi constantemente en esta constitución, habla del pecado original (GS 13). El Concilio vuelve a recordarnos las terribles circunstancias en que nos encontramos, y la enorme fuerza del pecado. Va a volver a hablar del pecado original, y lo define paladinamente como un pecado histórico. Por eso, no es atribuible a la creación de Dios, sino al curso de la historia; es decir, al hombre, definiéndolo explícitamente como un acto de soberbia, de separación de Dios, como un gesto que implica un desprecio. Pero si se da de nuevo la reconciliación el pecado podrá ser sanado. 
Ha de ser sanado en la historia porque fue cometido en la historia: «Creado por Dios en la justicia, el hombre, sin embargo, por instigación del demonio, en el propio exordio de la historia, abusó de su libertad, levantándose contra Dios y pretendiendo alcanzar su propio fin al margen de Dios» (GS 13).

Como he dicho, hay aquí una definición del pecado, y no solo del original, como rebeldía contra la gloria debida a Dios y por ello como gloria a un ídolo, una criatura. ${ }^{25}$ El efecto es el embrutecimiento de la mente y del corazón. El Concilio indica que esto es una revelación, y que, por tanto, no puede ser negada por los que creen en la revelación.

Pero que, por otra parte, es algo que coincide con la experiencia. No se trata de que coincida la definición de pecado simplemente, sino la revelación del pecado histórico del origen. Y la razón que da es que los males y la inclinación al mal no puede tener su origen en el Santo Creador del hombre. Pero también coincide la esencia del pecado original con la de todo pecado, nacido de la inclinación al mal, de la indebida subordinación de los fines y del egoísmo en las relaciones humanas. Sabemos el bien, pero el mal nos atrapa y convence.

El Concilio indica que ese embrutecimiento, esa escalada de estupidez, va a tener otros efectos secundarios, especialmente la división interior, la guerra entre el bien y el mal, y la esclavitud consiguiente. «Conocieron a Dios, pero no le glorificaron como a Dios. Obscurecieron su estúpido corazón y prefirieron servir a la criatura, no al Creador» (Rom $1,21-25)$.

25 «Conocieron a Dios, pero no le glorificaron como a Dios. Obscurecieron su estúpido corazón y prefirieron servir a la criatura, no al Creador». 
La idolatría consiste esencialmente en amar a la criatura, en amar lo que no puede dar vida, lo muerto, es decir, lo inferior al hombre. Su efecto es un círculo vicioso, puesto que no se sale de la misma criatura.

En esos efectos ve el Concilio las terribles circunstancias y desequilibrios en que se encuentra actualmente la historia humana, pero también su sanación. Porque la luz de la Revelación del estado del hombre, del origen de su pecado y del futuro que le aguarda, auxiliado por la gracia, puede hacer volver al hombre en sí: «Pero el Señor vino en persona para liberar y vigorizar al hombre, renovándole interiormente y expulsando al príncipe de este mundo (cf. Io 12,31), que le retenía en la esclavitud del pecado [...] El pecado rebaja al hombre, impidiéndole lograr su propia plenitud» (GS 13).

Que todo lo anterior es una declaración de tipo dogmático, y por tanto, para ser creída, se expresa claramente en esta frase final: «A la luz de esta Revelación, la sublime vocación y la miseria profunda que el hombre experimenta hallan simultáneamente su última explicación» (GS 13).

\subsection{CONSTITUCión DEL HOMBRE (GS 14)}

Y sigue la declaración dogmática: «En la unidad de cuerpo y alma, el hombre, por su misma condición corporal, es una síntesis del universo material, el cual alcanza por medio del hombre su más alta cima y alza la voz para la libre alabanza del Creador» (GS 14).

El Concilio ha unido la definición del hombre, innegable, de criatura racional, individual y libre a la condición social de él mismo como origen y vocación. Y ahora lo une a su vocación de dominio del mundo, de administrador de él y del mismo mundo, por su dimensión material. 
Es la segunda característica que va a resaltar el documento, que, por tanto, se abre al mundo. En esta segunda afirmación recoge lo dicho antes:

No debe, por tanto, despreciar la vida corporal, sino que, por el contrario, debe tener por bueno y honrar a su propio cuerpo, como criatura de Dios que ha de resucitar en el último día. Herido por el pecado, experimenta, sin embargo, la rebelión del cuerpo. La propia dignidad humana pide, pues, que glorifique a Dios en su cuerpo y no permita que lo esclavicen las inclinaciones depravadas de su corazón. (GS 14)

Si el pecado es un desorden -y lo es- que hace que lo que no debe regir, rija al hombre, la salvación debe ser lo contrario. Pero, aparentemente, esto es excesivamente formal. Sin embargo, dirá varias veces que la salvación consiste en poder amar (GS 17), y que en no amar a Dios sobre todas las cosas y al prójimo, sino mi propia inclinación, consiste el pecado.

No obstante, las propias inclinaciones se oponen y obnubilan la razón que discierne el bien, y la conciencia que impera. Luego, en el fondo, está diciendo que no debe el ser humano dejarse llevar sino por la ley divina. ${ }^{26}$

26 Dos afirmaciones complementarias. La primera es de un verdadero amor al cuerpo, como parte del hombre y síntesis del universo material, es decir, instrumento de encuentro con la naturaleza y los demás hombres, llamado a la resurrección. Pero la segunda es que lo racional debe regir lo corporal y no al contrario, puesto que en el pecado hay una rebelión, un desorden, en el que las pasiones irracionales vencen al deber y a la voluntad de Dios. 
Ahora viene una afirmación antimaterialista que funda lo anterior:

No se equivoca el hombre al afirmar su superioridad sobre el universo material y al considerarse no ya como partícula de la naturaleza o como elemento anónimo de la ciudad humana. Por su interioridad es, en efecto, superior al universo entero; a esta profunda interioridad retorna cuando entra dentro de su corazón, donde Dios le aguarda, escrutador de los corazones, y donde él personalmente, bajo la mirada de Dios, decide su propio destino. (GS 14)

Esta es la base sobre la que podrá indicar al mundo su verdadera vocación a la unidad, fundada en la superioridad del ser humano sobre todo lo demás. Por tanto, lo proclama fin en sí mismo: «Al afirmar, por tanto, en sí mismo la espiritualidad y la inmortalidad de su alma, no es el hombre juguete de un espejismo ilusorio provocado solamente por las condiciones físicas y sociales exteriores, sino que toca, por el contrario, la verdad más profunda de la realidad» (GS 14).

Considero que las principales afirmaciones de tipo dogmático sobre la dignidad del hombre ya están dichas. Hemos de recordar la tradición de la Iglesia, especialmente los concilios $\mathrm{V}$ de Letrán, donde se define la espiritualidad e inmortalidad del alma humana (COD 605-606; MSI 32, 842; DZ 1440) que recoge el de Vienne y que viene completado con la Humani Generis (DS 3896). Este habla de la inmediata creación del alma humana en el momento de la concepción.

En principio se oponía a cierto panteísmo, determinismo o materialismo que a lo largo de la historia ha despreciado al hombre concreto. Ahora, tras las hecatombes de las guerras europeas, con motivo muy especial, 
la afirmación de la espiritualidad del alma, que el Papa Juan Pablo II va a afirmar en la Evangelium Vitae con mayor fuerza, sirve para que al hombre se le considere y se respete en su dimensión trascendente, por encima de lo material. Además, creo que eso, exactamente, quiere decir, sin caer en espiritualismos platónicos desencarnados.

También recuerda el Concilio el magisterio irreformable el decreto del Concilio de Trento sobre el pecado original (DS 1510-1516) que recoge el concilio de Cartago y el Arausicano II, ${ }^{27}$ y que es fundamental para no caer en el pelagianismo, anticipo del ateísmo moderno y heredero del fariseísmo. Si Dios no es necesario, la fe resulta también innecesaria. De eso a no pensar en Dios y a no orar, no hay más que un paso.

\subsection{El Sagrario Del hOMbre (GS 15-16)}

En lo más profundo de su conciencia descubre el hombre la existencia de una ley que él no se dicta a sí mismo, pero a la cual debe obedecer, y cuya voz resuena, cuando es necesario, en los oídos de su corazón, advirtiéndole que debe amar y practicar el bien y que debe evitar el mal: haz esto, evita aquello. Porque el hombre tiene una ley escrita por Dios en su corazón, en cuya obediencia consiste la dignidad humana y por la cual será juzgado personalmente. La conciencia es el núcleo más secreto y el sagrario del hombre, en el que éste se siente a

27 «Si alguno afirma que la prevaricación de Adán le dañó a él solo y no a su descendencia; que la santidad y justicia recibida de Dios, que él perdió, la perdió para sí solo y no también para nosotros; o que, manchado él por el pecado de desobediencia, solo transmitió a todo el género humano la muerte y las penas del cuerpo, pero no el pecado que es muerte del alma: sea anatema, pues contradice al Apóstol que dice: "Por un solo hombre entró el pecado en el mundo, y por el pecado la muerte, y así a todos los hombres pasó la muerte, por cuanto todos habían pecado" (Rm 5, 12)». 
solas con Dios, cuya voz resuena en el recinto más íntimo de aquélla. Es la conciencia la que de modo admirable da a conocer esa ley cuyo cumplimiento consiste en el amor de Dios y del prójimo. La fidelidad a esta conciencia une a los cristianos con los demás hombres para buscar la verdad y resolver con acierto los numerosos problemas morales que se presentan al individuo y a la sociedad. Cuanto mayor es el predominio de la recta conciencia, tanto mayor seguridad tienen las personas y las sociedades para apartarse del ciego capricho y para someterse a las normas objetivas de la moralidad. No rara vez, sin embargo, ocurre que yerra la conciencia por ignorancia invencible, sin que ello suponga la pérdida de su dignidad. Cosa que no puede afirmarse cuando el hombre se despreocupa de buscar la verdad y el bien y la conciencia se va progresivamente entenebreciendo por el hábito del pecado. (GS 16, el resalte es nuestro)

A partir de aquí el Concilio celebra los éxitos de la inteligencia humana, pero indica que le es necesaria la «sabiduría», "la cual atrae suavemente la mente del hombre a la búsqueda y al amor de la verdad y del bien». Se habla de lo «invisible» para afirmar valores que no son simplemente materiales, como el plan divino de la salvación de los hombres (GS15), y como la conciencia moral. Esta descubre la ley de Dios escrita en el corazón (GS 16), cuya observancia confiere al hombre su dignidad (al contrario del pecado que lo rebaja, como decía al final el número 13).

Quisiera resaltar lo que he subrayado. La dignidad del ser humano depende del cumplimiento de esa ley que la conciencia le dicta. Un ser humano adquiere dignidad por la escucha de Dios y la pierde cuando hace oídos sordos a Dios. 
Y Dios habla en la conciencia a través de la ley natural que la conciencia, o razón humana, descubre en el intento por servir al bien y a la verdad. Así pues, el Concilio afirma la unidad de esta ley en todos los hombres, de modo que lo que nos une fundamentalmente sería el mismo Señor que la ha puesto en todos, y de ahí que la Revelación y la Razón estén profundamente en comunión.

Las normas de Dios, aunque la conciencia las discierne, son objetivas. Por ello, el escepticismo o relativismo moral se opone profundamente al Concilio: «La orientación del hombre hacia el bien solo se logra con el uso de la libertad, la cual posee un valor que nuestros contemporáneos ensalzan con entusiasmo. Y con toda razón. Con frecuencia, sin embargo, la fomentan de forma depravada, como si fuera pura licencia para hacer cualquier cosa, con tal que deleite, aunque sea mala» (GS 17).

Hay una referencia directa al relativismo también en el número 28 :

Esta caridad y esta benignidad en modo alguno deben convertirse en indiferencia ante la verdad y el bien. Más aún, la propia caridad exige el anuncio a todos los hombres de la verdad saludable. Pero es necesario distinguir entre el error, que siempre debe ser rechazado, y el hombre que yerra, el cual conserva la dignidad de la persona incluso cuando está desviado por ideas falsas o insuficientes en materia religiosa. Dios es el único juez y escrutador del corazón humano. Por ello, nos prohíbe juzgar la culpabilidad interna de los demás.

No es conveniente extendernos más sobre este tema. La dignidad del ser humano, su vocación, está en la libertad, es decir en la autónoma determinación por lo más justo, por lo más verdadero, por lo mejor. Por eso, 
por el carácter personal del ser humano, el diálogo con Dios en el seno de la conciencia, aunque determinado por el bien objetivo, es un diálogo siempre humano y no debe existir en él la coacción que convierte al ser humano en objeto y no en sujeto de sus propias acciones. ${ }^{28}$

\section{1. «LA LIBERTAD HUMANA, HERIDA POR EL PECADO, PARA DAR LA MÁXIMA EFICACIA A ESTA ORDENACIÓN A DIOS, HA DE APOYARSE NECESARIAMENTE EN LA GRACIA DE DIOS. CADA CUAL TENDRÁ QUE DAR CUENTA DE SU VIDA ANTE EL TRIBUNAL DE DIOS SEGÚN LA CONDUCTA BUENA O MALA QUE HAYA OBSERVADO»(GS 17)}

Nos llama la atención ese texto precioso sobre la dignidad y grandeza de la libertad. Llama libertad a la capacidad humana de descubrir y decidirse por el bien. No niega la herida, pero afirma que cumplir la vocación a esa libertad es la fuente de la dignidad humana, como antes había dicho en el número 16. Pero es necesario resaltar dos ideas que van a fundar la incoherencia del ateísmo con una antropología verdaderamente humana: la existencia, espiritualidad y libertad del alma y su inmortalidad, por un lado, que hacen vislumbrar el juicio particular que revela la Escritura y la necesidad también

28 «La verdadera libertad es signo eminente de la imagen divina en el hombre. Dios ha querido dejar al hombre en manos de su propia decisión para que así busque espontáneamente a su Creador y, adhiriéndose libremente a este, alcance la plena y bienaventurada perfección. La dignidad humana requiere, por tanto, que el hombre actúe según su conciencia y libre elección, es decir, movido e inducido por convicción interna personal y no bajo la presión de un ciego impulso interior o de la mera coacción externa. El hombre logra esta dignidad cuando, liberado totalmente de la cautividad de las pasiones, tiende a su fin con la libre elección del bien y se procura medios adecuados para ello con eficacia y esfuerzo crecientes» (GS 17). 
de la gracia para cumplir la propia vocación. Con esto el Concilio cree haber respondido a la primera pregunta: ¿Qué es el hombre?

Pero la afirmación de la dignidad, espiritualidad del alma y caducidad de la vida, así como de la apertura del hombre a Dios y la necesidad que tiene de Él, invitado estructuralmente a dialogar con Él, ${ }^{29}$ nos aboca a la segunda pregunta. Se trata de aquella sobre la muerte, y esta conducirá a la tercera, la pregunta sobre el ateísmo, que aparece en este contexto como un verdadero irracionalismo.

Por eso ahora se pregunta ¿qué sentido tiene el dolor y «la muerte» ${ }^{30}$ ?. Es el tema escatológico que es respondido así por el Concilio en el N. 18 con tres afirmaciones: (a) la vida en el más allá; (b) la declaración de que la muerte no ha sido querida por Dios, sino que es consecuencia del pecado, ${ }^{31}$ y (c) la necesidad de buscar a Dios en todo instante en esa perspectiva.

29 «La razón más alta de la dignidad humana consiste en la vocación del hombre a la unión con Dios. Desde su mismo nacimiento, el hombre es invitado al diálogo con Dios. Existe pura y simplemente por el amor de Dios, que lo creó, y por el amor de Dios, que lo conserva. Y solo se puede decir que vive en la plenitud de la verdad cuando reconoce libremente ese amor y se confía por entero a su Creador» (GS 19).

30 «El máximo enigma de la vida humana es la muerte. El hombre sufre con el dolor y con la disolución progresiva del cuerpo. Pero su máximo tormento es el temor por la desaparición perpetua. Juzga con instinto certero cuando se resiste a aceptar la perspectiva de la ruina total y del adiós definitivo. La semilla de eternidad que en sí lleva, por sí irreducible a la sola materia, se levanta contra la muerte» (GS 18).

31 Es interesante resaltar aquí la referencia clara al magisterio de la Iglesia Concilio Cart. XVI DS 241: «Can. 1. Plugo a todos los obispos [...] congregados en el santo Concilio de la Iglesia de Cartago: Quienquiera que dijere que el primer hombre, Adán, fue creado mortal, de suerte que tanto si pecaba como si no pecaba tenía que morir en el cuerpo, es decir, que saldría del cuerpo no por castigo del pecado, sino por necesidad de la naturaleza, sea anatema». 
El Concilio intenta aquí simplemente mostrar lo que se deriva de la fe en la Revelación. ${ }^{32}$ Se deriva la Esperanza y la seguridad que procede de Cristo, que da sentido al sufrimiento y a la muerte, efectos del pecado, del que ha hablado antes, y del que hemos referido la cita tridentina. ${ }^{33} \mathrm{~A}$ partir de la redención, la muerte, efecto del pecado, pierde su carácter de maldición para volverse el instrumento del amor, primero en Cristo, después en nosotros. La muerte, por otro lado, es estrictamente individual, separa de los seres queridos. También, por la resurrección de Cristo, dejará de tener

32 Profesión de fe: «Mientras toda imaginación fracasa ante la muerte, la Iglesia, aleccionada por la Revelación divina, afirma que el hombre ha sido creado por Dios para un destino feliz situado más allá de las fronteras de la miseria terrestre. La fe cristiana enseña que la muerte corporal, que entró en la historia a consecuencia del pecado, será vencida cuando el omnipotente y misericordioso Salvador restituya al hombre en la salvación perdida por el pecado. Dios ha llamado y llama al hombre a adherirse a Él con la total plenitud de su ser en la perpetua comunión de la incorruptible vida divina. Ha sido Cristo resucitado el que ha ganado esta victoria para el hombre, liberándolo de la muerte con su propia muerte. Para todo hombre que reflexione, la fe, apoyada en sólidos argumentos, responde satisfactoriamente al interrogante angustioso sobre el destino futuro del hombre y al mismo tiempo ofrece la posibilidad de una comunión con nuestros mismos queridos hermanos arrebatados por la muerte, dándonos la esperanza de que poseen ya en Dios la vida verdadera» (GS18).

33 1. Si alguno no confiesa que el primer hombre Adán, al transgredir el mandamiento de Dios en el paraíso, perdió inmediatamente la santidad y justicia en que había sido constituído, e incurrió por la ofensa de esta prevaricación en la ira y la indignación de Dios y, por tanto, en la muerte con que Dios antes le había amenazado, y con la muerte en el cautiverio bajo el poder de aquel que tiene el imperio de la muerte (Hebr 2, 14), es decir, del diablo, y que toda la persona de Adán por aquella ofensa de prevaricación fue mudada en peor, según el cuerpo y el alma (v. 174): sea anatema. 2. Si alguno afirma que la prevaricación de Adán le dañó a él; solo y no a su descendencia; que la santidad y justicia recibida de Dios, que él perdió, la perdió para sí solo y no también para nosotros; o que, manchado él por el pecado de desobediencia, solo transmitió a todo el género humano la muerte y las penas del cuerpo, pero no el pecado que es muerte del alma: sea anatema, pues contradice al Apóstol que dice: Por un solo hombre entró el pecado en el mundo, y por el pecado la muerte, y así a todos los hombres pasó la muerte, por cuanto todos habían pecado (Rom 5, 12). 
ese carácter de soledad, para unirnos con ellos. Es una afirmación, esta del magisterio, muy interesante: el cielo no es simplemente de gente solitaria, es una relación nueva con Dios y los demás.

En conclusión, la Gaudium et Spes dice que el ser humano, siendo histórico, realiza su vocación en la historia. No obstante, esta tiene en Cristo su punto de apoyo, su clave y su fin. 


\section{BIBLIOGRAFÍA}

Alcalá, Manuel

1998

Sinodos, concilios, iglesias. Madrid: BAC 2000.

AnTón, Ángel

1987

El Misterio de la Iglesia. Evolución histórica de las ideas eclesiológicas. Madrid: BAC.

GonZÁlez Montes, Adolfo

2008

Imagen de Iglesia. Eclesiología en perspectiva ecuménica. Madrid: BAC.

LATOURELLE, René

1989

Vaticano II, Balance y Perspectivas. Veinticinco años después (1962-1987). Salamanca: Colección Verdad e Imagen. Sígueme.

Martín Descalzo, José Luis

1967

El concilio de Juan y Pablo. Documentos pontificios sobre la preparación, desarrollo e interpretación del Vaticano II. Madrid: BAC.

Rovira Belloso, Josep M.

1997

Vaticano II, un concilio para el tercer milenio. Madrid: BAC 2000. 
VV. AA.

1966

Concilio Vaticano II. Comentarios a la Constitución sobre la Iglesia. Madrid: BAC.

VV. AA.

1967

Comentarios de Cuadernos para el diálogo al Esquema XIII. Madrid: Edicusa.

VV. AA.

1968

Concilio Vaticano II. Comentarios a la constitución Gaudium et Spes sobre la Iglesia en el mundo actual. Madrid: BAC.

VV. AA.

1969

Concilio Vaticano II. Comentarios a la Dei Verbum sobre la divina revelación. Madrid: BAC.

VV. AA.

1969

Los sacerdotes. Salamanca: Taurus.

VV. AA.

1970

La Iglesia en el mundo de hoy. Salamanca: Taurus.

VV. AA.

1968

Las relaciones de la Iglesia con las religiones no cristianas. Salamanca: Taurus.

VV. AA.

1969

La libertad religiosa. Salamanca: Taurus. 
CÉSAR BUENDÍA

VV. AA.

1969

La liturgia después del Vaticano II. Salamanca: Taurus.

VV. AA.

1970

La revelación divina. Salamanca: Taurus. 